\title{
Entrelacé: How technology, movement and visuals are interlaced in the film design for The Royal Ballet's Woolf Works
}

\author{
John Hillman \\ Birmingham City University \\ Parkside, 5 Cardigan Street \\ Birmingham B4 7BD, UK \\ john.hillman@bcu.ac.uk
}

\author{
Ravi Deepres \\ Birmingham City University \\ Parkside, 5 Cardigan Street \\ Birmingham B4 7BD, UK \\ ravi.deepres@bcu.ac.uk
}

\begin{abstract}
The Royal Ballet's Woolf Works, directed by Wayne McGregor, expresses multidisciplinary thinking by combining choreography, technology and design through the mediums of dance, sound, film, light and space. This paper will consider how movement and visual projections are interconnected through the film sequences produced by Ravi Deepres for 'Wolf Works.' Each film sequence uses different technologies to express Deepres' conceptual ideas relating to Virginia Woolf and her writing. These include the use of super slow motion technologies, architectural scanning and 3D modelling. The sequences were all embedded into the performance and were integral to the overall narrative structure. On stage the film sequences were presented cinematically, at huge scale, as part of a transformation of the dance performance space into a cinematic experience. While the sequences played other design forms such as movement, choreography, sound and light unified the overall performance. Articulating the working methods and processes of Deepres' practice, the paper will examine the successes and challenges of the project. It will also offer a philosophy of working that integrates the collaboration of different disciplines (choreography, sound, music and cinema) with new technologies. One of the case studies that will be presented is 'The Waves', a film sequence, shot in super slow motion using a Phantom Gold camera at Godrevy lighthouse (one of the locations Woolf visited frequently in Cornwall). The footage begins as a virtually static image then builds over a period of 25 minutes, a duration rarely used with this technology. In the paper Deepres will detail his conceptual approach and the technological challenges associated with producing and displaying the work. The paper will ultimately articulate a real world example of the relationship between artist, technology and performing arts. It will ask how the layers of narrative, articulated through multiple mediums and expressed through a range of technology, can operate at both a dependent and also independent level.
\end{abstract}

Film. Ballet. Performance. Cinematic. Technology. Movement. Virginia Woolf. Methods. Theory.

\section{INTRODUCTION}

In the previous century it was film and moving images that would often provide a context for thinking about questions relating to the human condition. Not by directly framing such questions, but by configuring the basic dilemmas of human existence into a new and interpretable form. In this way, film became an object through which ideas could be expressed and understood. This ontological exploration film and cinema brought about a new kind of subjectivity: one shaped from and through cinematic experience (Rodowick 2017). It is of course true that we are probably only able to reflect back upon the significance of film and cinema as we enter a changing period: a period in which the heterogeneous spaces of screens and interactive media offer very different experiences.

In "Reading the Figural, or Philosophy After New Media" (2001), David Rodowick applies the concept of the figural as way of understanding an apparent breakdown in semiotic or linguistic forms of analysis. He argues a challenge to the standard theoretical approaches to aesthetics comes from new media, technology and other digital forms. For Rodowick contemporary media is not well served by understanding it through semiotic analysis. He suggests what is needed is the concept of the figural. This concept encompasses: a wider sense of semiotic analysis; a social theory that 
interrogates the aesthetic as commodity; and a means to read how contemporary life is reorganised by new image forms and technology (Rodowick 2001).

In the Twenty First Century, as the formal theatrical staging of film loses its philosophical ground to an environment of multi-mediated images, we might consider the multidisciplinary thinking embodied in Wayne McGregor's Woolf Works (2017) as an example of a new hybrid and figural aesthetic. What follows is an account of how Woolf Works interlaces technology, movement and visuals in an expression of the figural.

\section{TECHNOLOGY, MOVEMENT AND VISUALS}

Combining choreography, technology and design through dance, sound, film, light and space, Woolf Works articulates itself via multiple mediums and a range of different technology. It incorporates analogue mediums such as dance and performance, with digital projections of moving images, 3D scanning and $360^{\circ}$ panoramas. This interlacing between different forms is suggestive of the overall lack of distinction that permeates many contemporary experiences, such that at any time we may well be simultaneously watching, listening, interacting and being distracted.

Core components of the staging of Woolf Works in this interlaced way are Ravi Deepres' visual projections. These projections function as an integral part of the overall narrative structure. They are embedded within and enhance the dance performances, supporting and supplementing the movement on the stage. At the Royal Ballet in London, Deepres' moving image sequences were presented in large scale, transforming the dance and performance stage into a new space that recalled traditional cinematic experiences, yet at the same time the work questioned these very conditions. While the sequences played, movement, choreography, sound and light unified the overall performance.

Centred around the co-existence of dance, film projection, light, sound, space and texts, the production produced what can be described as a figural encounter with the life and work of Virginia Woolf. Here, the figural relates to a different mode or way of signifying. In this way, representation itself appears to be changing, such that multimediated experiences inaugurate a new and different regime of signs (Rodowick 2001). This means the underlying logic of the production cannot be simply understood through conventional linguistic or aesthetic analysis. It's meaning is conveyed, not through the simple relationship of an image to a word or an expression to a thought, rather the entire performance becomes image in another sense: a complex of sensations, perceptions and affects.

In Act One, black and white archive and contemporary documentary footage are interwoven together to trace the journeys of the characters in Woolf Works. The film includes scenes from locations in London, reflecting aspects of one of Woolf's books, 'Mrs Dalloway' (1925). In this book the central character, Clarissa Dalloway, travels around London in preparation for a party.

During the performance, the film was projected onto and through revolving wooden frames designed by architectural designers Ciguë (see Figure 1). The structuring of this part of the performance works against the conventional idea of an image projected onto the surface of a screen. Instead, there is a frame that encloses nothing. And it is only on the frame itself that images are visible.

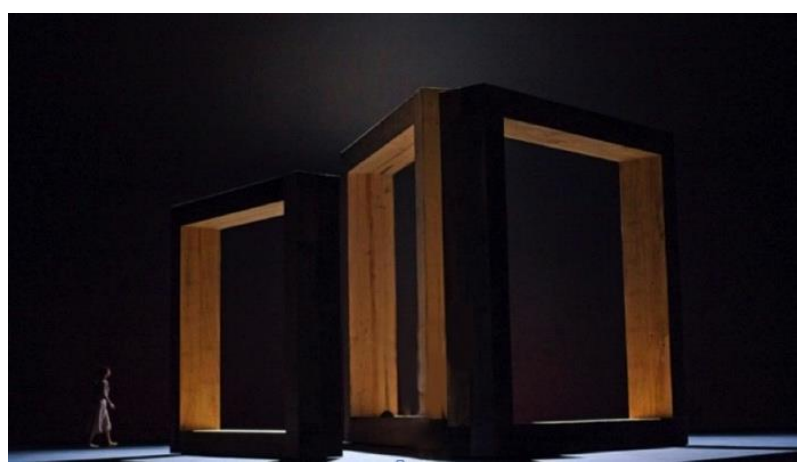

Figure 1: The wooden frames designed by architectural designers Ciguë.

What the audience sees is a fragmenting of the film as it becomes visible only when light falls upon the limited vertical and horizontal surfaces of the revolving wooden frames. The film appears at the edges and not on any large flat surfaces, as might usually be expected. Here, we might read this as suggestive of how image is open, implied and unfilled. It is also, of course, a framing of the inescapable emptiness that defines the characters themselves. As symbolic identity is ostensibly absent in the empty space inside the frame, it is also equally trapped by the visible movement in space and across historical time.

In this particular piece Deepres worked with found footage, piecing together narratives through a process of associative thinking. The black and white film has an aspect ration of $4: 3$ and was produced in $1440 \times 1080$ resolution. This format was then mapped onto the shape of the wooden frames on the stage.

Toward the end of Act One a moving image piece of a LIDAR (Light Detection and Ranging) laser 
scanned image of Monks House in East Sussex, once owned by Virginia Woolf, is projected onto the stage. LIDAR scanning is traditionally used in architecture and surveying. It uses a pulsed laser and measures the return times to construct a 360degree 3D model of a space. Deepres made use of a LIDAR scanning system to create what appears as a ghosted but rendered three-dimensional model of Monks House and its garden (see Figure 2).

In this piece, objects emerge from skeletal structures as the camera moves and pans around the space. While the intention, when it was projected, was to create an aesthetic quality similar to impressionist painting, it cannot be ignored that the basis of this work is mathematical rather than optical, is computational rather than perceptual: here algorithms and lasers create a different kind of image. This kind of work inevitably represents the disappearance of photography: there is no drawing with visible light here. It also signals the weakening relationship between object and image, between a certain notion of indexicality that is usually linked to photography. While we know Monks House exists in East Sussex, what we see is strictly limited in its visual relationship to the actual house. The virtual house, as seen through the LIDAR scan, is no more or no less mediated than any other symbolic representations. But there is something distinctly constructed about this piece. It appears as both indexical and virtual. Moreover, the way in which the camera moves through the space and the way objects appear and disappear, does not obfuscate the process of image making. In a camerasaturated world, we have become used to taking for granted the position and movement of the camera: it has become naturalised. However, it is the virtual, dematerialised, image that is the reference point for this work. There can be no escaping the sense in which image has been created through a different method, such that there is something uncanny and yet also something familiar about what we see.

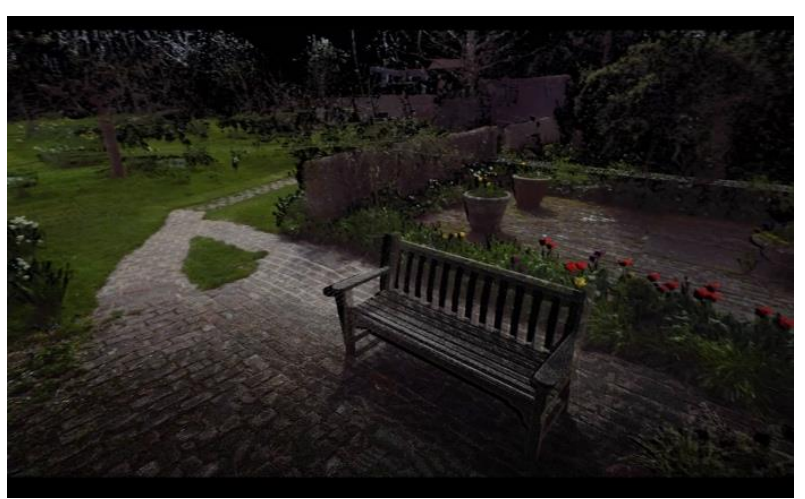

Figure 2: Screenshot of 3D LIDAR scan of Monks House.
The illusion of image is, perhaps, exaggerated when image itself is in someway illusionary. In this virtual construction of space, perhaps the only truly authentic aspects are the calculations, which make the illusion of image possible.

Another example of the interlacing between choreographic expression and projection happens in Act Three, when Deepres film sequence 'The Waves' is projected onto the stage (see Figure 3). The sequence, shot in super slow motion begins as a virtually static image, which builds over a period of twenty-five minutes. The ambition for 'The Waves' was to create a moving photograph. Using a high speed Phantom Gold camera, the footage was shot at Godrevy lighthouse in Cornwall. Captured in the middle of a storm, the film sequence depicts the shifts and movements of the ocean in exquisite detail. Accompanied by Max Richter's musical score, the edge-blended panorama is projected high onto the stage using three projectors.

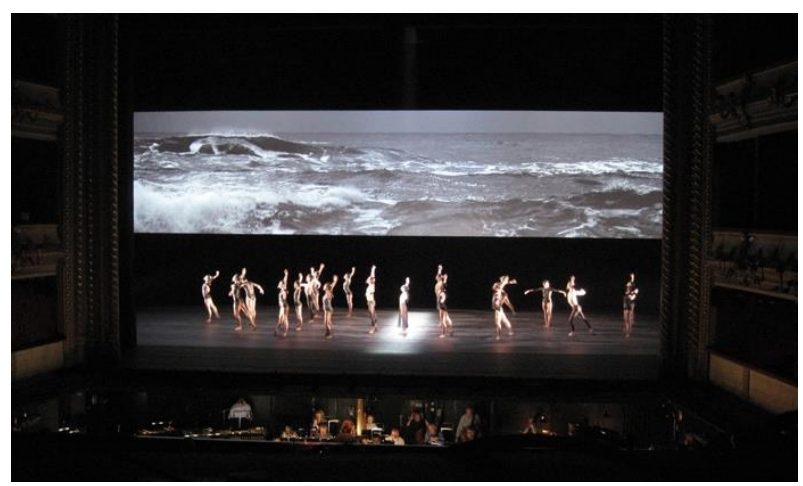

Figure 3: The Waves.

At the early stages of the project, Deepres explored the routes Woolf walked in and around the St lves area. His aim was to encapsulate in his work the resonances he thought she would have experienced. Godrevy was identified as one location frequently visited by Woolf and it became the location setting for this particular piece. One of the key technical challenges, while working at Godrevy during a storm, was data capture. The duration of over twenty minutes that Deepres was shooting for was rarely used with the Phantom Gold technology. The Phantom CineMag - fast, high capacity, hard drives - were essential to ensure the footage was captured complete and in full. The Phantom Gold shot at 1/1000 frames per second at $1920 \times 540$ resolution. In post-production the footage was slowed down further using Adobe Premiere and the Twixter plug-in. The cropping balances the moving image above the stage with the dance performance beneath it. Within the context of Woolf Works, Deepres' work needed to adapt to the dynamics of the performance production. Therefore, tweaks and refinements 
were made to timing and length during the rehearsal phase.

The inspiration underlying Act Three was Virginia Woolf's own interest and creative use of the transformative power of nature and the shifting of time in her own work. Of course, the entire production of Woolf Works attempts to reflect the innovations of Virginia Woolf's writing through different contemporary forms. The creative decisions, relating to the presentation of the 'The Waves' were focused on the transformation of the performance space. In Act Three, as the moving image is revealed, there is a shift from the wide screen cinematic presentation of the moving image through to the physicality of the choreography. 'The Waves' is revealed on stage from behind a black curtain. Its epic scale is designed, like cinema, to immerse the audience in a visual experience. But due to the film being shot in super slow motion, the image appears frozen, paused and immobile. As the film plays, the words from Virginia Woolf's suicide note are spoken by an actor. Here, a dialectical relationship between movement and stillness is articulated through what we perceive as a moving photograph and the live performance on the stage. Since a photograph expresses a form of immobility, revealing something movement appears to hide, then movement and visibility are in someway negatively linked. The counterpointing of McGregor's live choreography and Deepres' sequentially stilled images of movement conveys something of Virginia Woolf's state of emotional confusion.

The elements, as they are brought together in this final act, attempt an interrogation of duration. The extended film sequence reveals the usually invisible details that structure the movement of the ocean. Here, one can understand the repetitive motion of the waves, together with the movements of the dancers on the stage, as invoking a kind of continuous and unceasing reinvention. What we see and what is revealed, is always in some way contingent. So, as duration changes, so does our perception.

\section{CONCLUSION}

If the figural describes something of the logic of mass culture, then how can it be used to describe the structure and aesthetics of a ballet such as Woolf Works? I suggest the answer lies in how digital technology can infiltrate the domain of the analogue. In supporting and enhancing a condition of the analogue reality, the digital also changes the co-ordinates of that reality. In Woolf Works it seems as though there is less of difference between the analogue aspects of the performance and the digital projections and moving images. The gap between them is reducing to the extent that one becomes integral to the other.

In Woolf Works, the textured combination of dance, film, sound and movement expresses an implicit relation to Virginia Woolf and her life. Each of the elements establishes a space for another virtual overlaying of thoughts and memories, which help underwrite the performance. As Gilles Deleuze notes, when writing on Francis Bacon, an artist never really confronts a blank canvas (Deleuze 2002/1981) and of course neither does an audience.

\section{REFERENCES}

Deleuze, G. (2002/1981) Francis Bacon: The logic of sensation. Continuum, London.

McGregor, W. (2017) Woolf Works. (Ballet), 21 $1^{\text {st }}$ January $-14^{\text {th }}$ February 2017, The Royal Ballet, Royal Opera House, London.

Rodowick, D. N. (2001) Reading the Figural, or Philosophy After the New Media. Duke University Press, Durham.

Rodowick, D. N. (2017) What Philosophy Wants from Images. The University Press of Chicago, Chicago.

Woolf, V. (1925), Mrs Dalloway. Hogarth Press, London. 